\title{
Computer-based interactive health communications for people with chronic disease
}

This article was published in the following Dove Press journal:

Smart Homecare Technology and TeleHealth

8 April 2014

Number of times this article has been viewed

\section{Leanne M Casey' \\ Bonnie A Clough' \\ Mary E Mihuta' \\ Heather Green' \\ Wayne Usher ${ }^{2}$ \\ Daniel A James 3,4 \\ David D Rowlands ${ }^{3}$ \\ E-Liisa Laakso ${ }^{5}$}

'Griffith Health Institute Behavioural Basis of Health Program, School of Applied Psychology, ${ }^{2}$ School of Education and Professional Studies, ${ }^{3}$ Sports and Biomedical Engineering Laboratory, School of Engineering, Griffith University, Queensland, Australia; ${ }^{4}$ Centre of Excellence for Applied Sport Science Research, Queensland Academy of Sport, Queensland, Australia; ${ }^{5} \mathrm{Griffith}$ Health Institute Centre for Musculoskeletal Research, School of Allied Health Sciences, Griffith University, Queensland, Australia
Correspondence: Leanne M Casey School of Applied Psychology, Griffith University, 176 Messines Ridge Road, Mt Gravatt Campus, QLD 4I I I, Australia Tel+6I 737353314

Email l.casey@griffith.edu.au
Abstract: Chronic diseases (CD) - such as cardiovascular, diabetes, cancer, and chronic respiratory diseases - are projected to be the most common causes of mortality and morbidity by 2030. Use of a participatory decision-making model that emphasizes a partnership among practitioners, patients, and their families to achieve desired goals is a key strategy in achieving optimal outcomes. The Interactive Health Communication Applications (IHCAs) can support participatory decision making by providing the unique infrastructure needed to deliver support for the multiple requirements of patients with $\mathrm{CD}$. The aim of this paper is to provide a descriptive review of the use of IHCAs in the treatment of chronic disease. Patient acceptability and satisfaction were identified as key issues that can be enhanced by ensuring that IHCAs provide: 1) emotional support and empowerment; 2) education and information from health professionals; and 3) telecommunication instead of onsite visiting. An important benefit of IHCAs can be an improved quality of communication between the patients and the health care professionals, which is a critical and predictive factor of treatment outcomes for many patients with CD. Similarly, there is good evidence to suggest that IHCAs can improve the patients' adherence to both medication and behavioral regimens designed to both treat and manage CDs. However, it is important to recognize that the technological development and effective implementation of an ICHA is a complex multidisciplinary operation that needs to take into account the needs of the various stakeholders as well as making use of the most suitable technology.

Keywords: chronic disease, computer-based, interactive health communication

\section{Introduction}

Ten years ago, a number of forecasts were made in relation to the expected impact of Interactive Health Communication Applications (IHCAs) on 21st century health care delivery.

According to Haux et al, ${ }^{1}$ three major goals needed to be achieved if ICHA was to achieve its full potential. These goals were identified as being: 1) the integration of a patient-centered e-health recording system that supported medical data for cooperative care; 2) a highly effective and efficient process-integrated decision support platform; and 3) a comprehensive and seamless ability to use patient data for research and health care reporting. Haux et $\mathrm{al}^{1}$ also argued that modern health information system architectures, comprehensive electronic patient records, specific data processing methods (known as "medical data mining") and multifunctional mobile information and communications technology (ICT) tools would be required for 21 st century health care to keep pace with societal demands and expectations concerning e-health information recording and dissemination. 
In this paper, we examine the extent to which these goals and expectations have been met in the area of chronic diseases (CD) by summarizing current developments in computerbased interactive health care and investigating the impact of this form of health care upon people with CD. A discussion of the participatory decision-making model in health care is provided, with reference to the treatment of CD. As CDs are a largely heterogeneous group of conditions, rather than providing an exhaustive review of the IHCAs currently available for each condition, we focus on the overall patient perceptions of these interventions, acceptability and satisfaction, and patient adherence to the IHCA interventions. We also examine the challenges in effective implementation of interactive computer delivery. Thus, a more transdiagnostic approach was utilized throughout this review, which is designed to provide a descriptive summary of the current state of research in this field. Similarly, this review examines the range of technologies that are now available rather than limiting the focus to one specific type of technology. Our aim is to provide an overview of this emerging area, to stimulate research and clinical practice.

\section{Participatory decision-making model in health care}

Approximately $80 \%$ of the CDs around the globe are from cardiovascular, diabetes, cancer, and chronic respiratory diseases. ${ }^{2}$ Death rates are rising rapidly and are projected to be the most common causes of mortality and morbidity by 2030. Some 125 million Americans are living with one or more CDs, such as diabetes, heart disease, or lung disorders. ${ }^{2}$ In Australia, CD currently contributes to around $70 \%$ of the total burden of illness and injury. ${ }^{3}$

Chronic diseases "involve the total human environment for supportive care, maintenance of function, and prevention of further disability". "Given the nature and complexities in treating and managing such diseases, there is a shift toward adopting a participatory decision-making (PDM) model as the preferred model of health care delivery in the early twenty first century. ${ }^{5}$ The critical components of such an approach are "the partnership among practitioners, patients, and their families ... to ensure that decisions respect patients wants, needs, and preferences and solicit patients' input on the education and support they need to make decisions and participate in their own care". ${ }^{6}$ Importantly, the PDM model is associated with better outcomes in patients with a CD. ${ }^{7}$

Many health professionals are embracing modern ICT platforms in an attempt to strengthen the PDM model as the preferred model of treatment in the clinical encounter and treatment of CD. ${ }^{8,9}$ E-health strategies need to be formulated to respond to the specific target population, reflecting the existing CD demography and neighborhood socioeconomic characteristics. ${ }^{10}$ IHCAs provide unique infrastructure needed to address and to provide support for the multiple requirements of patients with CD. Accordingly, a recent review of outcomes associated with IHCAs found improvements in users' knowledge, social support, health behaviors, clinical outcomes, and self-efficacy. ${ }^{11}$

Modern communication technologies are giving rise to what is more commonly referred to as "mobile health" or "m-health". Underpinning such a delivery model are technologies, which include the Internet, email, software applications, playing media, iPhones, smartphones, BlackBerrys, various Android phones, PC tablets, phablets, health Apps, and wireless monitoring devices (eg, MedApps [Alere ${ }^{\mathrm{TM}}$ Connect, Scottsdale, AZ, USA] and Toumaz [Toumaz Group, London, UK]).

Such mobile wireless communication technologies share a common thread and goal whereby they simplify the human-computer interface by creating a more streamlined process. Such e-platforms when bundled with innovative technologies, such as health applications, smartphones, and PC tablets, will create environments that will be, as Boulos et $\mathrm{al}^{12}$ predicted, useful to the medical- and health-related professions. The extent to which mobile health is impacting on twenty first century health care delivery is evident by recent research predicting that "the number of mobile health care and medical apps downloaded will reach 142 million globally by $2016 " .{ }^{13}$

E-health technologies are heightening participatory models and making them a more acceptable part of clinical practice by creating e-platforms where health care delivery integrates a number of emerging health technologies. The underpinning commonalities of these e-health technologies are their unique ability to link relevant services and data storage capabilities, which collectively promotes networkability, multimodalities, interactivity, and usability. ${ }^{14}$ Mobile platforms are powerful enablers that can be used to provide education and feedback about the treatment and/or rehabilitation process being undertaken while allowing interventions to be undertaken where required. ${ }^{15-17}$ In an early example of how IHCA can be used to affect lifestyle behaviors, Hurling et $\mathrm{al}^{18}$ tested an Internet, email, and mobile phone behavior change system to deliver an automated physical activity program in a randomized controlled trial (RCT) of healthy adults and measured the accelerometer data and self-reports of physical activity. The authors found that use of the behavior 
change system significantly increased and maintained the level of physical activity in the intervention group compared with the control group. There was also significantly greater perceived control and intention/expectation to exercise and a greater loss of percentage of body fat in the intervention group compared to the control group.

Furthermore, Rolim et al ${ }^{19}$ identified that for the successful integration of modern health technologies into future health care environments, there will need to be a number of considerations given to the current health care ecosystem concerning institutional policies, practices, and infrastructure. Accordingly, Rolim et a ${ }^{19}$ have suggested a number of considerations to enhance the successful adoption of health technologies. These include: 1) the collection of patient's vital data; 2) network flexibility; 3) security of use and integration; 4) high levels of privacy for patient and health professional; 5) compatible with other computing devices; 6) high levels of reliability; 7) able to be applied to both large and small health care settings; and 8) inexpensive, low-profile computing devices.

\section{Patient perceptions of acceptability, satisfaction, quality of life}

To reap the benefits of IHCAs in CD, it is important to consider the consumers' perceptions of these technologies. Patient acceptability and satisfaction are key issues, together with patient-reported outcomes, such as health-related quality of life (HRQOL).

Acceptability of technology in relation to health can be defined in terms of intention or willingness to use the technology and actual use or adoption of the technology. ${ }^{20}$ Several models have been proposed regarding the acceptability of information technology. Adapting from earlier work, Davis ${ }^{21}$ developed a technology acceptance model, which posited that perceived usefulness and ease of use influence intention to use a technology, which consequently influences actual use of the technology. Davis ${ }^{21}$ later expanded this model to include the additional predictors of performance expectancy, effort expectancy, social influence, and facilitating conditions, as outlined in the Unified Theory of Acceptance and Use of Technology.22 Their tests of the model also showed that moderators of intention included age, sex, experience with the technology, and the voluntariness of use. ${ }^{22}$ These two models were further adapted by other authors in a health context as the patient technology acceptance model, which was developed to understand acceptability of health technology for older adults with CD. ${ }^{23}$ This model included additional variables, grouped as patient-centered factors, attitudes toward technology, computer anxiety, computer self-efficacy, and perceived behavioral control.

An important theme that has emerged from empirical studies on the consumer acceptability of ICT in health care is that consumer perceptions depend highly on the frequency of ICT use. ${ }^{24}$ Furthermore, such perceptions are generally based on how well the technology provides: 1) emotional support and empowerment; 2) education and information from health professionals; and 3) telecommunication instead of onsite visiting. ${ }^{25}$

To date, a number of studies have evaluated patient acceptability of ICT in health care management in individuals with CD. One such study that assessed the acceptance of a computerized counseling program for facilitating physical activity in individuals with $\mathrm{CD}$ found that the overall acceptance of the program was good but patient perceptions about the usefulness of the tool varied. ${ }^{26}$ Another study assessing the feasibility, functionality, and usability of a patient-led cancer care web platform found that patients perceived the website as useful, but many found it too complex to use. ${ }^{27}$ Issues regarding difficulty of use, low self-efficacy, and anxiety related to the use of a home telecare management system have been reported in patients with congestive heart failure and chronic obstructive pulmonary disease. ${ }^{28}$ The patients' perceptions of the usefulness of electronic medical records have also been evaluated in patients with chronic inflammatory bowel disease and the results indicated that providing access to Internet-based electronic medical records had little usefulness to patients on its own, without being actively made useful in conjunction with health care professionals. ${ }^{29}$ These findings indicate that for patients to gain positive perceptions of ICT use in their health care management, the technologies must be useful and userfriendly, which ought to be considered in the development and implementation of ICT systems.

Mobile platforms can also enhance the delivery of existing rehabilitation services that have proven efficacy but poor participation rates. For example, Varnfield et $\mathrm{al}^{30}$ tested a smartphone and web application (the Care Assessment Platform), combined with telephone mentoring to enhance outcomes of cardiac rehabilitation, and identified that the IHCA was practical and easy to use, with very high average rates (above 90\%) for compliance, indicated by the usage of the device to collect the most data, except alcohol intake and smoking. Given that alcohol intake and smoking are critical factors in the development of $\mathrm{CD}$, the technology and its method of application requires further work. However, in an 
RCT of the intervention, the Care Assessment Platform was demonstrated to be marginally more cost-effective than the traditional rehabilitation approach. ${ }^{31}$

Patient satisfaction is another important outcome measure to consider when assessing patients' perceptions of IHCAs, and it is also an important indicator for measuring the quality of health care. ${ }^{32}$ Patient satisfaction is a multidimensional construct that evaluates a variety of patient expectations and experiences, including patient expectations as consumers, patient views about the information, and the communication they receive related to their condition, perceptions about the provider's competence and caring, and the coordination and integration of the care received. ${ }^{33,34}$ There is evidence suggesting that the integration of IHCAs in health care has the ability to improve patient satisfaction, ${ }^{35-37}$ but most of the research has assessed patient satisfaction in private practices or hospital settings and with single technology systems. ${ }^{34}$

There appears to be a gap in the literature - with little research having been conducted - that evaluates the use of telehealth outside health care settings, which is a critical aspect of health care for chronically ill patients. There is the capacity for future research to assess patient satisfaction related to IHCAs at home, because this has the potential to improve overall quality of care in this clinical group.

A finding that may seem counterintuitive is that one of the most discernible benefits acquired from IHCAs may be an improved quality of communication between the patients and the health care professionals, which is a critical and predictive factor of treatment outcomes for many patients with CD. ${ }^{38}$ Having an increased accessibility to health professionals by using interactive communication systems, such as messaging, the Internet, and teleconferencing, provides consumers with additional medical support. As a result, these patients and their caregivers have reported increased feelings of security and safety ${ }^{39}$ and increased feelings of wellness to help them achieve a functioning daily life. ${ }^{40}$ It would be expected that these outcomes would also be associated with increased patient satisfaction.

Another aspect to consider regarding patient-reported outcomes is the potential impact of IHCAs on HRQOL. In chronically ill patients, HRQOL is viewed as subjective, multidimensional, dynamic, and includes aspects of physical, psychological, and social function. ${ }^{41,42}$ Patients at home using IHCAs have expressed an increased sense of independence and autonomy in managing their own illnesses, which has been shown to decrease levels of distress and depression and to improve the overall quality of life. ${ }^{43}$

\section{IHCAs to increase patient adherence}

IHCAs have also been investigated as a method for increasing patient adherence to treatment programs. Adherence may be thought of as the extent to which a person's behaviors follow the advice given by health care professionals. ${ }^{44-46}$ This can include entering a treatment program, maintaining a treatment program, keeping aftercare appointments, modifying behaviors and lifestyle, and taking prescribed medications. ${ }^{46,47}$

Problems with adherence can often lead to poorer clinical outcomes. ${ }^{48}$ Although adherence to medications has been estimated at approximately $50 \%$, adherence with behavioral regimens is often even lower. ${ }^{48}$ Aside from poorer treatment outcomes, low client adherence can also result in a poor use of resources, staff and patient time, and increased costs associated with treatments. ${ }^{47}$

Increasing patient adherence to treatment processes is a complex issue. Although many theories and models of adherence exist, there is, as yet, limited evidence of effective interventions to increase patient adherence. Indeed, a recent meta-analysis found that the only interventions to produce long-term increases in patient adherence to medications involved complex, resource-intensive approaches. ${ }^{49}$

However, it was also found that even among these studies, the observed effect sizes were small, with improvements in adherence and treatment gains being minor. ${ }^{49}$ Findings such as these have led to a recent increase in studies examining IHCAs as a strategy to increase patient adherence. IHCAs may be able to provide a cost-effective, patient- and providerinteractive solution to the issue of adherence, with possible increased treatment effect sizes..$^{50,11}$ The current section provides a descriptive review of the use of IHCAs to improve adherence among patients with $\mathrm{CD}$, specifically in relation to adherence to medications and behavioral regimens.

\section{IHCAs to increase patient adherence to medications}

Among patients with $\mathrm{CD}$, nonadherence to medications is a common difficulty, often leading to increased morbidity, mortality, and health care costs. ${ }^{50}$ IHCAs have been investigated with relation to medication adherence for many chronic health conditions, including diabetes, hypertension, asthma, and cardiovascular conditions. ${ }^{51-53}$

A recent review was conducted of IHCAs aimed at increasing adherence among the patients prescribed cardiovascular and diabetes medications. ${ }^{50}$ This review 
identified 13 RCTs. Interventions ranged from one-way reminder systems to interactive interventions delivered by telephone, using voice recognition technology and interactive computer media interventions. The review found that there was an overall lack of high-quality research in this area, but that current results indicate IHCAs have the potential to facilitate increased patient adherence to medications, albeit with small effect sizes. The review found the strongest evidence for the efficacy of the electronic reminder systems, as opposed to the more complex interactive systems. ${ }^{50}$

IHCAs have also been used to facilitate increased patient adherence to medications among patients with asthma. These interventions typically involve online monitoring of symptoms, health education, counseling, feedback, and prompts regarding medication use. Jan et $\mathrm{al}^{54}$ found that an Internetbased interactive program was able to improve patient monitoring of asthma symptoms significantly and adherence with asthma medications over the course of a 12-week RCT. These increased adherence rates led to improved clinical outcomes among the intervention sample. However, it is important to note that effect sizes were not reported in this trial nor was the follow-up data for the sample.

The results of Jan et $\mathrm{al}^{54}$ are supported by other studies in the field, such as that by Rasmussen et al. ${ }^{55}$ In this study, it was demonstrated in an RCT of 300 adults with asthma that an IHCA was able to increase the patient's adherence to asthma medication, improve clinical outcomes, and improve the patient's quality of life. ${ }^{55}$ Although effect sizes were not reported for this study, it provides supporting evidence concerning the long-term positive effects of IHCAs in the area of patient adherence to medications.

\section{IHCAs to increase patient adherence to behavioral regimens}

Recent studies have shown IHCAs to be a promising intervention for increasing patient adherence to behavioral regimens. These regimens can include activities such as self-monitoring, management of symptoms, and lifestyle changes.

A recent review examined the effectiveness of IHCAs to assist in the self-monitoring of symptoms among youth with chronic health conditions. ${ }^{56}$ The authors identified nine RCTs, of which seven displayed positive effects relating to increased client adherence in self-monitoring and improved treatment outcomes when compared to control conditions.

Ryan et $\mathrm{al}^{57}$ reported on an Internet-based IHCA to assist low-income patients with type 2 diabetes monitor blood glucose levels and receive health-related information and support. They found low patient adherence to the program, with patients recording glucose levels into the online system approximately twice per week rather than once per day, and using the health application once per week rather than every second day. However, the authors found that the patients who used the IHCA more frequently experienced improved outcomes for diabetes. High costs associated with the 13-month trial were also reported. These included the costs of providing participants with computers, Internet connection, computer literacy training, technological support and repairs, and diabetes-specific treatment equipment. ${ }^{57}$

IHCAs have also been used to facilitate patient adherence to weight loss regimens among overweight and obese women who were at an increased risk of developing breast cancer ${ }^{58}$ and other chronic illnesses, such as hypertension. ${ }^{59}$ While many studies have reported the positive effects of IHCAs at increasing adherence to behavioral regimens, others have found no additional benefits from the use of the online programs when compared to control conditions. ${ }^{60}$

There are many theories of adherence, however many studies to date report on the efficacy of IHCAs that have been developed without reference to one of these theories. Efficacy of IHCAs may be able to be improved if the technologies are developed based on current models and theories of patient adherence. Furthermore, many studies fail to report effect sizes for interventions, and lack methodological rigor.

\section{Challenges of effective implementation}

The implementation of any technology-based health strategy is usually complex and multidimensional. The challenges include the technological development itself, cost recovery, as well as adoption by what may be a resistant community of differing stakeholders.

All technology is rapidly evolving with new technologies constantly appearing in the market, which has two main effects. It either supersedes the current technology, or it is an enabler/aggregator, which ties a group of technologies together. It is the enabler/aggregator aspect that allows the aforementioned interconnectedness of technology, allowing the technology to pervade many areas of everyday living.

An example is the smartphone, which ties together communications systems, personal data assistant systems, and computing/networking systems. Moore's law is a widely held maxim that is commonly used to describe the evolution of technology. Moore's law theorizes that technology will roughly double in complexity every 2 years ${ }^{61}$ with a corresponding miniaturization and cost reduction of about 
the same magnitude. The implication is that technology will become faster, more powerful, smaller, and cheaper every 2 years. Thus, in the design of any new technology or e-health system where the project design cycles (typically, 2 years or more) are of the order of Moore's law, then the completed technology will be out of date at the time of its release. Hence, it is the application of the technology that becomes more important rather than just the technology itself. Thus, the propensity for the convergence of similar technologies to coalesce into a single device has emerged and been found useful for e-health applications; for example, Rowlands et $\mathrm{al}^{62,63}$ utilized a smartphone - as a survey instrument, information website, and personal health monitor - as a convergence of a health activity sensor ${ }^{64}$ and e-health gateway. ${ }^{65}$

In the smartphone example, an internal minimum viable product using a single smartphone supported by a back-end cloud-based server was developed. The implementation used a sensor to capture movement, which was aggregated by the smartphone, and sent to the cloud-based server. ${ }^{62}$

The role of the cloud-based server was twofold. First, the server needed to collect incoming data from multiple participants and store the data in a database. Second, it needed to be able to transform and to serve the data via a web interface to the participants and the health care professional. The website that was developed also allowed for the education of the participant. The web pages could be accessed using the smartphone or any web-enabled device through the use of a browser. In the implementation, data security was maintained using an internal intranet with secure sockets layer (SSL) 128-bit level security, as well as defined policies on access and password protection. These are well-known, wellaccepted, and commonly available procedures that allowed the development to be accelerated.

The implemented system was developed by a multidisciplinary team, who - through focus group discussions developed a user requirement, which was then rolled out to a technology trial before beta testing with a group of high-adherence users. Following the internal trial, a clinical cohort was identified for future testing. Interactive user feedback was developed and used as a basis for follow-up focus group testing. ${ }^{63}$

Of course, it is not the technology alone that constitutes the provision of new services and opportunities, but the integration of the technology that captures and leverages or automates the expertise of health professionals. Without the value added for the health professional, then the uptake and acceptance of the technology will be very low, since there is little to no extra benefit to them using it over the methods that they are currently employing.

The challenge in gaining acceptance of these new technologies requires interactions and understanding of the three main stakeholder groups: 1) health professionals and scientists working in a research organization; 2) end users of the technology, such as patients, outpatients, interested consumers, and community dwellers; and 3) commercial partners.

While the three groupings embarking on the technological development share some common goals or desires, they come from very different organizational cultures where different expectations, methods of communication, language, and processes are prevalent.

Research organizations - whether pure or applied - are focused on the creation of new knowledge. This may include new methods and the application of frontier technologies. By the very nature of this focus, outcomes can challenge existing ideas and perceptions and are generally viewed as a high-risk activity that can be expensive.

Any new technologies developed may be somewhat raw initially, including functional rather than sophisticated devices, complex operations, and outcomes for a lay person. Individuals in these groups are committed to sharing this knowledge in the worldwide community and may be less interested in the implementation of technologies into everyday use. Organizationally, individuals are encouraged to be free thinking and unaccustomed to short-term deadlines and commercial considerations, such as design for mass manufacture.

Medical organizations are primarily focused on the delivery of health services in what is increasingly a servicedriven model, with low overheads and dependence on approved transactional processes. These organizations are often hierarchical, driven by long certification processes and are traditionally slow adopters because of the consequences of failure; they adopt evidence-based approaches through lengthy trial periods. User groups may include the unwilling, reluctant participants as well as those motivated self-help individuals who are interested in consumer products for lifestyle monitoring. The introduction of technology to both organizations and individuals can be challenging for the existing culture. Harding et $\mathrm{al}^{66}$ introduced a personalized physical activity technology into sport as a personal tool, as well as an automated expert, which could then be used by an early adopter user base of the technologically literate. Even so, both community perception and resistance to the technology were variable, suggesting this would appear to be a best possible scenario for a medical technology equivalent. 
The development of technology is usually accompanied by development costs and lengthy testing processes in an iterative cycle until a product (internal or commercial) is ready for release. In all cases, developers of technology need to satisfy their stakeholders or investors that there is likely to be a good return on investment through technology adoption, successful interventions, and/or product sales.

Development of the products requires a well-established business plan from prototype to mass manufacture to projected sales. Technologies developed must use components with favorable cost, availability, and reliability; the requirements for the technology are often that it needs to be unique or first to market. The developed technology should attract sufficient sales to return to investors approximately ten times the investment. Often, the consumer market is the only way to achieve this. Regular and close interaction between all of the groups is essential for novel technologies to be developed, trialed, and rolled out to commercial production.

Successful commercialization of any technology requires the identification of the market, costs to bring to market, and the model of income generation or cost recovery in the event of internal use. In the case of software for a smartphone-based system developers should consider not only the developer cost,${ }^{64}$ but that of offering support, whether the software will be restricted to a few models and versions of an operating system and whether back-end cloud-based systems are scalable. A model where additional computer processing units can be used in times of high load is also a consideration. Cost recovery of any medical technology is critical to the success of the technology, as high-capital cost items limit market penetration. Many medical product firms, particularly in information technology, opt for a transactional-based cost recovery.

In either case, approval to bill the costs directly either by transaction, service, or a service that relies on the technology as a health care-approved cost code is essential for direct medical industry support from its professionals.

Another key consideration is the technological literacy and time overhead for use. This is quite often forgotten or understated in the development of technology. If the technology is not intuitive and easy to use, then it is not likely to be received strongly. If the technology requires that the user undergoes formalized training in the use of the product, then it is also not likely to be received positively. Of course, this will vary with the background, experience, and expectation of return of the user. If aiming the ICHA or service for use in the general community, then it should be simple, quick, and easy to use. If the device takes too long to set up or is unwieldy to use, then uptake is unlikely. The study by Rowlands et $\mathrm{al}^{63}$ found that one of the confounding issues with the technology was the involvement of the human factor.

A final challenge of effective implementation is providing feedback to the user in a viable and meaningful form. This will be different for each stakeholder. The health care professional will want the data in a form that can be manipulated to allow varying levels of scientific analysis. The user will require the information presented in a form that is easy to digest and that tells them something essential without having to mine data or analyze the data to any depth.

This feedback requires a multidisciplinary approach using: 1) technologists to generate the feedback on the IHCA and let the other team members know what is possible; 2) psychologists to assess effectiveness and develop presentation; 3) health care professionals to determine what information is required; and 4) educational designers to develop appropriate interfaces that will create change and ensure its sustainability.

Overall, the technologic development and effective implementation of an ICHA is a complex multidisciplinary operation, which needs to take into account the needs of the various stakeholders as well as drawing together the most suitable technology.

\section{Conclusion}

The aim of this paper was to provide a descriptive review of IHCAs within the treatment of CDs. IHCAs can support participatory decision making by providing the unique infrastructure needed to deliver support for the multiple requirements of patients with CD. Given the heterogeneous nature of $\mathrm{CDs}$, this review focused on the broader aspects concerning implementation and the uptake of these interventions. Patient perceptions and acceptability of these services are key to the successful uptake of IHCAs. Research suggests that IHCAs have the potential to increase patient satisfaction with treatment services and promote an improved QOL.

IHCAs may also be useful in promoting patient adherence to medication and behavioral regimens, leading to improved treatment outcomes. However, as discussed, the implementation of these technologies is not without challenges. The collaboration between key stakeholders and careful attention to user needs and capabilities will be vital in realizing the further potential in this area to improve health care for patients with chronic diseases.

The current research indicates that IHCAs have the potential to improve and to change considerably the way 
in which patients with CDs communicate with health professionals, seek information, and monitor and engage in treatments. Future research and practice within this area will likely be influenced by technological developments, such as Web 3.0. While previous Internet-based tools (Web 1.0) and current social media (Web 2.0) configurations/ platforms proliferate in the health care environment, creating a mass collaboration between content creator and user, the new technology (Web 3.0) will be based on intelligent web applications using: 1) natural language processing; 2) machine-based learning and reasoning; and 3) intelligent applications. The architecture underpinning Web 3.0 will allow a heightened tailoring of online information searches and requests - specifically geared to the users' preferences and needs. Such configurations will allow users: to maximize search results; have access to open-source software platforms; and to minimize the time-related tasks associated with online health information retrieval, service searching, and medical dialogue. Another advantage to the emerging Web 3.0 space is that it will be a very fast and customizable application that can run and be supported by any device, computer, or mobile platform, and it will have open access to global databases (cloud data).

However, even with such technological advances, it is important that the development of IHCAs be guided by patients and practitioners. Future research needs to be led by consumers, rather than assessing need and satisfaction on a post hoc basis. This integration of scientist-practitioner development will likely facilitate improved uptake and integration of the technologies, potentially overcome some of the current challenges in implementation, and lead to improved treatment outcomes for patients. With the various technological applications that underpin the participatory decisionmaking model, the future of health care delivery promises much in its efforts to create those environments where the patient is central to self-managed treatment of CD.

\section{Disclosure}

The authors report no conflicts of interest in this work.

\section{References}

1. Haux R, Ammenwerth E, Herzog W, Knaup P. Health care in the information society. A prognosis for the year 2013. Int J Med Inform. 2002;66(1-3):3-21.

2. World Health Organization. Global Status Report on Noncommunicable Diseases. Geneva: World Health Organization; 2010. Available from: http://whqlibdoc.who.int/publications/2011/9789240686458_eng. pdf?ua=1. Accessed December 11, 2013.
3. Australian Bureau of Statistics. National Health Survey: summary of results, 2007-2008 (reissue). Available from http://www.abs.gov.au/ AUSSTATS/abs@.nsf/Latestproducts/4364.0Main\%20Features12007$2008 \% 20$ (Reissue) opendocument $\&$ tabname $=$ Summary \&prodno $=$ $4364.0 \&$ issue $=2007-2008 \% 20$ (Reissue $) \&$ num $=\&$ view $=$. Accessed December 11, 2013.

4. Bousquet J, Anto JM, Sterk PJ, et al. Systems medicine and integrated care to combat chronic noncommunicable diseases. Genome Med. 2011;3(7):43.

5. Parchman ML, Zeber JE, Palmer RF. Participatory decision making, patient activation, medication adherence, and intermediate clinical outcomes in type 2 diabetes: a STARNet study. Ann Fam Med. 2010;8(5): 410-417.

6. Institute of Medicine. Envisioning the National Health Care Quality Report. Bethesda, MD: Institute of Medicine; 2000. Available from http://www.nap.edu/openbook.php?isbn=030907343X. Accessed December 11, 2013.

7. Heisler M, Bouknight RR, Hayward RA, Smith DM, Kerr EA. The relative importance of physician communication, participatory decision making, and patient understanding in diabetes self-management. $J$ Gen Intern Med. 2002;17(4):243-252.

8. EPG Health Media. Healthcare Professional use of Mobile Devices: A comparative study between Europe and US in 2010 and 2012; 2012. Available from: http://www.epghealthmedia.com/docs/reports/mobilereport-abstract.pdf. Accessed December 11, 2013.

9. World Health Organization. mHealth: New Horizons for Health through Mobile Technologies: Second Global Survey on eHealth. Geneva: World Health Organization; 2011. Available from: http://www.who.int/goe/ publications/goe_mhealth_web.pdf. Accessed November 12, 2013.

10. Han JH, Sunderland N, Kendall E, Gudes O, Henniker G. Professional practice and innovation: Chronic disease, geographic location and socioeconomic disadvantage as obstacles to equitable access to e-health. HIM J. 2010;39(2):30-36.

11. Murray E, Burns J, See TS, Lai R, Nazareth I. Interactive Health Communication Applications for people with chronic disease [review]. Cochrane Database Syst Rev. 2005;4:CD004274.

12. Boulos MN, Wheeler S, Tavares C, Jones R. How smartphones are changing the face of mobile and participatory healthcare: an overview, with example from eCAALYX. BioMed Eng Online. 2011;10:24.

13. Mack J. The iPad in the Doctor's Office: Understanding What Physicians and Patients Desire from mHealth Applications. Newtown, PA: VirSci Corporation; 2012. Available from: http://www.pharma-mkting.com/ news/pmn118-article01.pdf. Accessed December 11, 2013.

14. Usher WT. Australian health professionals' social media (Web 2.0) adoption trends: early 21 st century health care delivery and practice promotion. Aust J Prim Health. 2012;18(1):31-41.

15. Boschen MJ, Casey LM. The use of mobile telephones as adjuncts to cognitive behavioral psychotherapy. Professional Psychology: Research and Practice. 2008;39(5):546-552.

16. Clough BA, Casey LM. Technological adjuncts to enhance current psychotherapy practices: a review. Clin Psychol Rev. 2011;31(3): 279-292.

17. Usher W, Laakso E, James D, Rowlands D. The connective matrix of emerging health technologies: E-Health solutions for people with chronic disease. International Journal of E-Health and Medical Communications. 2013;4(3):94-114.

18. Hurling R, Catt M, Boni MD, et al. Using internet and mobile phone technology to deliver an automated physical activity program: randomized controlled trial. J Med Internet Res. 2007;9(2):e7.

19. Rolim CO, Koch FL, Westphall CB, Werner J, Fracalossi A, Salvador GS. A Cloud Computing Solution for Patient's Data Collection in Health Care Institutions: Proceedings of eHealth, Telemedicine, and Social Medicine, ETELEMED '10, Second International Conference, St Maarten, The Netherlands Antilles, February 10-16, 2010. Los Alamitos, CA, USA: Conference Publishing Services; 2010. 
20. Or CK, Karsh BT. A systematic review of patient acceptance of consumer health information technology. $J$ Am Med Inform Assoc. 2009; 16(4):550-560

21. Davis FD. Perceived usefulness, perceived ease of use, and user acceptance of information technology. MIS Quarterly. 1989;13(3): 319-340.

22. Venkatesh V, Morris MG, Davis GB, Davis FD. User acceptance of information technology: Toward a unified view. MIS Quarterly. 2003;27(3):425-478.

23. Calvin KL, Karsh BT. The Patient Technology Acceptance Model (PTAM) for Homecare Patients with Chronic Illness. Proceedings of the Human Factors and Ergonomics Society Annual Meeting. 2006;50(10): 989-993.

24. Scalvini S, Baratti D, Assoni G, Zanardini M, Comini L, Bernocchi P. Information and communication technology in chronic diseases: a patient's opportunity. J Med Person. 2013:1-5.

25. Akesson KM, Saveman BI, Nilsson G. Health care consumers experiences of information communication technology - a summary of literature. Int J Med Inform. 2007;76(9):633-645.

26. Becker A, Herzberg D, Marsden N, Thomanek S, Jung H, Leonhardt C. A new computer-based counselling system for the promotion of physical activity in patients wtih chronic diseases - results from a pilot study. Patient Educ Couns. 2011;83(2):195-202.

27. Milne D, Sheeran L, Holmes M, Tidhar G, Aranda S. Trialling a patient-led cancer care website in an acute cancer care setting. Journal of Research in Nursing. 2012;17(6):538-554.

28. Rahimpour M, Lovell NH, Celler BG, McCormick J. Patients' perceptions of a home telecare system. Int J Med Inform. 2008;77(7):486-498.

29. Winkelman WJ, Leonard KJ, Rossos PG. Patient-perceived usefulness of online electronic medical records: employing grounded theory in the development of information and communication technologies for use by patients living with chronic illness. $J$ Am Med Inform Assoc. 2005;12(3):306-314

30. Varnfield M, Karunanithi M, Särelä A, et al. Uptake of a technologyassisted home-care cardiac rehabilitation program. Med J Aust. 2011;194(4):S15-S19.

31. Karunanithi M, Varnfield M, Ding H, Garcia E, Whittaker F, Särelä A. Care assessment platform: an ICT-enabled home care model for secondary prevention of cardiovascular diseases. Conf Proc IEEE Eng Med Biol Soc. 2010;2010:5266.

32. Messner ER. Quality of care and patient satisfaction: The improvement efforts of one emergency department. Topics in Emergency Medicine. 2005;27(2):132-141.

33. Zabada C, Singh S, Munchus G. The role of information technology in enhancing patient satisfaction. British Journal of Clinical Governance. 2001;6(1):9-16

34. Roham M, Gabrielyan AR, Archer NP. Predicting the impact of hospital health information technology adoption on patient satisfaction. Artif Intell Med. 2012;56(2):123-135.

35. Irani JS, Middleton JL, Marfatia R, Omana ET, D'Amico F. The use of electronic health records in the exam room and patient satisfaction: a systematic review. J Am Board Fam Med. 2009;22(5):553-562.

36. Kazley AS, Diana ML, Ford EW, Menachemi N. Is electronic health record use associated with patient satisfaction in hospitals? Health Care Manage Rev. 2012;37(1):23-30.

37. Rahimi B, Vimarlund V. Methods to evaluate health information systems in healthcare settings: a literature review. J Med Syst. 2007;31(5):397-432.

38. Agha Z, Schapira RM, Laud PW, McNutt G, Roter DL. Patient satisfaction with physician-patient communication during telemedicine. Telemed J E Health. 2009;15(9):830-839.

39. Olsson A, Engström M, Skovdahl K, Lampic C. My, your and our needs for safety and security: relatives' reflections on using information and communication technology in dementia care. Scand J Caring Sci. 2012;26(1):104-112.
40. Nilsson C, Ohman M, Söderberg S. Information and communication technology in supporting people with serious chronic illness living at home - an intervention study. J Telemed Telecare. 2006;12(4): 198-202.

41. Poradzisz M, Florczak KL. Quality of life: input or outcome? Nurs Sci Q. 2013;26(2):116-120.

42. Taylor RM, Gibson F, Franck LS. A concept analysis of health-related quality of life in young people with chronic illness. J Clin Nurs. 2008;17(14):1823-1833.

43. Williams GC, Lynch M, Glasgow RE. Computer-assisted intervention improves patient-centered diabetes care by increasing autonomy support. Health Psychol. 2007;26(6):728-734.

44. Friedman IM, Litt IF. Adolescents' compliance with therapeutic regimens: Psychological and social aspects and intervention. JAdolesc Health Care. 1987;8(1):52-67.

45. McDonald HP, Garg AX, Haynes RB. Interventions to enhance patient adherence to medication prescriptions: scientific review. JAMA. 2002;288(22):2868-2879.

46. Nosé M, Barbui C, Gray R, Tansella M. Clinical interventions for treatment non-adherence in psychosis: meta-analysis. Br J Psychiatry. 2003;183:197-206.

47. Chen A. Noncompliance in community psychiatry: a review of clinical interventions. Hosp Community Psychiatry. 1991;42(3):282-287.

48. Haynes RB, McDonald HP, Garg AX. Helping patients follow prescribed treatment: clinical applications. JAMA. 2002;288(22):2880-2883.

49. Haynes RB, Ackloo E, Sahota N, McDonald HP, Yao X. Interventions for enhancing medication adherence [review]. Cochrane Database Syst Rev. 2008;2:CD000011.

50. Misono AS, Cutrona SL, Choudhry NK, et al. Healthcare information technology interventions to improve cardiovascular and diabetes medication adherence. Am J Manag Care. 2010;16(12 Suppl HIT):SP82-SP92.

51. Cleland J, Caldow J, Ryan D. A qualitative study of the attitudes of patients and staff to the use of mobile phone technology for recording and gathering asthma data. J Telemed Telecare. 2007;13(2):85-89.

52. Nijland N, van Gemert-Pijnen JE, Kelders SM, Brandenburg BJ, Seydel ER. Factors influencing the use of a Web-based application for supporting the self-care of patients with type 2 aiabetes: a longitudinal study. J Med Internet Res. 2011;13(3):e71.

53. Weymann N, Härter M, Dirmaier J. A tailored, interactive health communication application for patients with type 2 diabetes: study protocol of a randomised controlled trial. BMC Med Inform Decis Mak. 2013;13:24.

54. Jan RL, Wang JY, Huang MC, Tseng SM, Su HJ, Liu LF. An internetbased interactive telemonitoring system for improving childhood asthma outcomes in Taiwan. Telemed J E Health. 2007;13:257-268.

55. Rasmussen LM, Phanareth K, Nolte H, Backer V. Internet-based monitoring of asthma: a long-term, randomized clinical study of 300 asthmatic subjects. J Allergy Clin Immunol. 2005;115(6): 1137-1142.

56. Stinson J, Wilson R, Gill N, Yamada J, Holt J. A systematic review of internet-based self-management interventions for youth with health conditions. J Pediatr Psychol. 2009;34(5):495-510.

57. Ryan JG, Schwartz R, Jennings T, Fedders M, Vittoria I. Feasibility of an internet-based intervention for improving diabetes outcomes among low-income patients with a high risk for poor diabetes outcomes followed in a community clinic. Diabetes Educ. 2013;39(3): 365-375.

58. Cadmus-Bertram L, Wang JB, Patterson RE, Newman VA, Parker BA, Pierce JP. Web-based self-monitoring for weight loss among overweight/obese women at increased risk for breast cancer: the HELP pilot study. Psychooncology. 2013;22(8):1821-1828.

59. Piette JD, Datwani H, Gaudioso S, et al. Hypertension management using mobile technology and home blood pressure monitoring: results of a randomized trial in two low/middle-income countries. Telemed $J$ E Health. 2012;18(8):613-620.

60. Miller DM, Moore SM, Fox RJ, et al. Web-based self-management for patients with multiple sclerosis: a practical, randomized trial. Telemed J E Health. 2011;17(1):5-13. 
61. Schaller RR. Moore's law: past, present and future. Spectrum, IEEE. 1997;34(6):52-59.

62. Yurish S, Reddy Y, Gervais-Ducouret S, Mauri JL, Gomez L, editors. Linking Sensor Data to a Cloud-based Storage Server Using a Smartphone Bridge. SENSORCOMM 2012, The Sixth International Conference on Sensor Technologies and Applications, Rome, Italy, August 19-24, 2012. International Academy, Research and Industry Association; 2012.

63. Rowlands DD, Usher W, McCarthy M, et al. An Automated Activity Monitoring System for Rehabilitation. Procedia Engineering. 2013;60:232-237.

64. James DA, Thiel DE, Allen KJ, et al. Technology and health: Physical activity monitoring in the free living environment. Procedia Engineering. 2012;34:367-372.
65. Laakso EL, Armstrong K, Usher W. Cyber-management of people with chronic disease: A potential solution to eHealth challenges. Health Education Journal. 2012;71(4):483-490.

66. Harding JW, Toohey K, Martin DT, Mackintosh C, Lindh AM, James DA. Automated inertial feedback for half-pipe snowboard competition and the community perception. In: Fuss FK, Subic A, Ujihashi S, editors. The Impact of Technology on Sport II. Oxon, UK: Taylor and Francis; 2007:845-850.

\section{Publish your work in this journal}

Smart Homecare Technology and TeleHealth is an international, peer-reviewed, open access online journal publishing original research, reviews, editorials and commentaries on the application of technology to support people and patients at home and in assisted living centers to optimize healthcare and management resources. Specific topics in the journal include: Development and application of devices within the home and embedded in appliances; Healthcare provider communication and education tools; and drug ordering and adherence. The manuscript management system is completely online and includes a very quick and fair peer-review system, which is all easy to use. Visit http://www.dovepress.com/ testimonials.php to read real quotes from published authors.

Submit your manuscript here: http://www.dovepress.com/smart-homecare-technology-and-telehealth-journal 